\title{
FURTHER OBSERVATIONS ON THE USE OF SOLAR ENERGY FOR REDUCING COFFEE-DRYING COSTS
}

An evaluation study of a solar-energy method for reducing coffee-drying costs was reported in the October 1963 issue of this Journal. ${ }^{1}$ The data for this at ticle we:e taken during the 1962 season. During the 1963 season, the experimental installation was successfully operated, and once again observations were made and data taken on the performance of this coffeedrying system.

During the period of observation, which extended from September 15 to November 22,1963 , the farm's production was 70 hundredweights. The yield for the season was lower than had been expected on this farm, and on other farms in the region. The electric-energy consumption for processing and drying was $874 \mathrm{kw}$.hr. during this period, corresponding to an average of $12.5 \mathrm{kw} . \mathrm{hr}$. per hundredweight of coffee produced. This figure is lower than the $20 \mathrm{kw}$.-hr. per hundredweight obtained in the 1962 season. This lower energy consumption may be attributed partly to greater dependence upon solar rather than electric energy, made possible by a more leisurely drying operation during the season of low yields.

Other factors may be that the predryer fan was in operating condition throughout the 1963 season, but not in the 1962 season, and that the operators had acquired more experience with the system in the second season.

The average daily solar energy available during various periods of the 1963 season were as follows: September 16 to $30,1,755$ B.t.u./ft. ${ }^{2}$; October 1 to $30,1,844$ B.t.u./ft. ${ }^{2}$; and November 1 to $12,1,718$ B.t.u./ft. ${ }^{2}$.

In the previous article, it was recommended that drying facilities be equipped with a fan with a capacity of 100 c.f.m. per square foot of bin area against a static pressure of a 1 -inch water gage. A subsequent study of airflow requirements has indicated that this figure is too high. It would be more practical to recommend a fan with a capacity of 50 c.f.m. per square foot of bin area against a static pressure of approximately 0.5 or 0.6 inches water gage.

Allan L. Phillips

Department of Agricullural Engineering

1 Phillips, A. L., A solar-energy method for reducing coffee-drying costs, $J$. .lgr. Cniv. P.R. 47(4): 22(i-35, 1963. 